\title{
Corrigendum: Gas chromatography mass spectrometry-based metabolite profiling in plants
}

Jan Lisec, Nicolas Schauer, Joachim Kopka, Lothar Willmitzer \& Alisdair R Fernie Nat. Protoc. 1, 387-396 (2006); published online 27 June 2006; corrected after print 5 August 2015

In the version of this article initially published, Figure 1 contained the words "metoxyamin hydrochloride." These words should have read "methoxyamine hydrochloride." The error has been corrected in the HTML and PDF versions of the article.

\section{Corrigendum: Primary culture of ovarian surface epithelial cells and ascites-derived ovarian cancer cells from patients}

Trevor G Shepherd, Brigitte L Thériault, Elizabeth J Campbell \& Mark W Nachtigal

Nat. Protoc. 1, 2643-2649 (2007); published online 11 January 2007; corrected after print 5 August 2015

In the version of this article initially published, in the Reagent Setup section, it was stated that $50 \% \mathrm{v} / \mathrm{v}$ Percoll should be made by diluting Percoll in 10x PBS at a 1:1 v/v ratio. Percoll should, in fact, be diluted in $2 \times$ PBS at a 1:1 ratio. The error has been corrected in the HTML and PDF versions of the article.

\section{Corrigendum: Measuring mRNA copy number in individual Escherichia coli cells using single- molecule fluorescent in situ hybridization}

Samuel O Skinner, Leonardo A Sepúlveda, Heng Xu \& Ido Golding

Nat. Protoc. 8, 1100-1113 (2013); published online 16 May 2013; corrected after print 19 August 2015

In the version of this article initially published, a component ( $40 \mu \mathrm{l}$ of $50 \mathrm{mg} \mathrm{ml}^{-1} \mathrm{BSA}$ ) was erroneously omitted from the 'Hybridization solution' recipe in the Reagent Setup section. The error has been corrected in the HTML and PDF versions of the article.

\section{Corrigendum: Efficient derivation and inducible differentiation of expandable skeletal myogenic cells from human ES and patient-specific iPS cells}

Sara M Maffioletti, Mattia F M Gerli, Martina Ragazzi, Sumitava Dastidar, Sara Benedetti, Mariana Loperfido, Thierry VandenDriessche, Marinee K Chuah \& Francesco Saverio Tedesco

Nat. Protoc. 10, 941-958 (2015); published online 4 June 2015; corrected after print 5 August 2015

In the version of this article initially published, the concentration of ROCK inhibitor Y27362 in Step 2 was incorrectly given as $10 \mathrm{mM}$. The correct concentration to be used is $10 \mu \mathrm{M}$. The error has been corrected in the HTML and PDF versions of the article. 